\title{
Brucellosis in Dogs and Public Health Risk
}

\author{
Martha E. Hensel, Maria Negron, Angela M. Arenas-Gamboa
}

Brucella canis infects dogs and humans. In dogs, it can cause reproductive failure; in humans, it can cause fever, chills, malaise, peripheral lymphadenomegaly, and splenomegaly. $B$. canis infection in dogs is underrecognized. After evaluating serologic data, transmission patterns, and regulations in the context of brucellosis in dogs as an underrecognized zoonosis, we concluded that brucellosis in dogs remains endemic to many parts of the world and will probably remain a threat to human health and animal welfare unless stronger intervention measures are implemented. A first step for limiting disease spread would be implementation of mandatory testing of dogs before interstate or international movement.

$B$ rucella canis is a gram-negative coccobacillary bacterium that primarily causes reproductive failure in dogs (1). The genus Brucella comprises 12 recognized species (2). Of these, B. melitensis, B. abortus, and B. suis are well-known causes of undulant fever and influenzalike symptoms in humans, but $B$. canis is less recognized as the cause of a zoonosis (3). In this review, we highlight information regarding occurrence of brucellosis in dogs, emphasizing $B$. canis as an underrecognized pathogen and describing current knowledge about its zoonotic potential.

\section{Epidemiology}

B. canis was initially characterized in 1966 after several outbreaks of abortion and infertility in dogs in multiple states (1). Since the discovery of B. canis as a cause of abortion, outbreaks in breeding and research kennels have been sporadically reported worldwide (4-7). The primary hosts are domesticated dogs; however, $B$. canis in wild canids and humans has also been reported $(8,9)$.

Brucellosis in dogs occurs worldwide and is endemic to the Americas, Asia, and Africa (Figure) (10). In the 1970s and early 1980s, serologic surveys of dogs from multiple countries demonstrated a wide range of seropositivity, from $1 \%$ to $28 \%$, depending on the country (online Technical Appendix, https://wwwnc.cdc.gov/EID/ article/24/8/17-1171-Techapp1.pdf). Within the past 30

Author affiliations: Texas A\&M University, College Station, Texas, USA (M.E. Hensel, A.M. Arenas-Gamboa); Centers for Disease Control and Prevention, Atlanta, Georgia, USA (M. Negron)

DOI: https://doi.org/10.3201/eid2408.171171 years, few studies have been conducted to evaluate disease occurrence and distribution in the United States, so the current status is unknown. However, in the past 2 decades, serologic studies of dogs have been published from countries in Africa, Asia, and South America and have reported moderate to high seroprevalence, ranging from $6 \%$ to $\approx 35 \%$ (online Technical Appendix). This wide range of seroprevalence could be attributed to multiple factors, including but not limited to true disease prevalence in the region or country, sampling design and study sample, and diagnostic test algorithm used.

B. canis infection in dogs occurs predominantly through ingestion, inhalation, or contact with aborted fetuses or placenta, vaginal secretions, or semen $(11,12)$. Like the rest of the Brucella species, B. canis exhibits tropism for reproductive tissue. Thus, infected dogs intermittently shed low concentrations of bacteria in seminal fluids and nonestrus vaginal secretions. Postabortion vaginal fluids contain a high level of bacteria and are a source of infection for other dogs and humans (11). Even after castration, dogs may still serve as a source of infection because the bacteria can persist in the prostate and lymphoid tissues $(13,14)$. In addition to in reproductive secretions, dogs can shed the bacteria in the saliva, nasal secretions, and urine $(11,15)$. Studies suggest that the concentration of B. canis in urine is higher in male than female dogs; this difference is attributed to urine contamination with seminal fluid (11). However, the role of urine as a source of infection is not fully understood.

\section{Clinical Manifestations in Dogs}

The clinical signs of $B$. canis infection are not pathognomonic. Dogs may be subclinically affected or may exhibit signs of reproductive failure. In male dogs, B. canis causes epididymitis, prostatitis, and orchitis (15); chronic testicular and epididymal inflammation can lead to unilateral or bilateral testicular atrophy and infertility (13).

The typical manifestation in females is mid- to lateterm abortion (during days 45-59), followed by an odorless, brown-to-yellow vaginal discharge for 1-6 weeks (1). Another manifestation is embryonic death with resorption, which appears as conception failure after an apparently successful mating (1). It is possible for an 


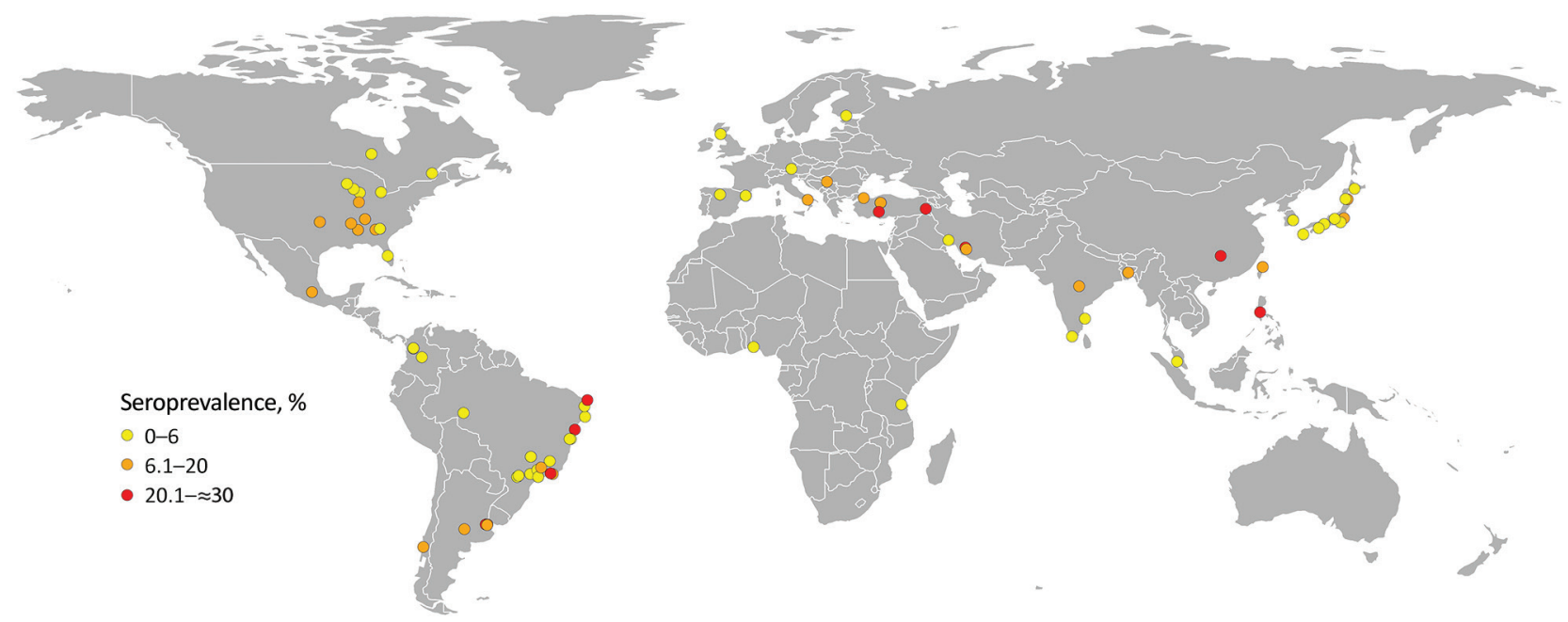

Figure. Locations of published Brucella canis serologic surveys of dogs (online Technical Appendix, https://wwwnc.cdc.gov/EID/ article/24/8/17-1171-Techapp1.pdf). Each dot represents 1 published study; colors represent seroprevalence determined in each study. Cartography: Cecilia Smith.

infected bitch to abort and subsequently have normal pregnancies or intermittently experience reproductive failure; these dogs may serve as reservoirs for infection in B. canis-naive dogs $(1,13)$. Aborted pups have nonspecific lesions, such as subcutaneous edema, hemorrhage, or congestion (1). Pups from infected bitches that survive may be infected in utero or through nursing and can be bacteremic yet appear healthy (13). It is possible for seemingly healthy puppies from an infected bitch to disseminate the bacteria to other dogs and to humans (16). Because $B$. canis infection is the most common cause of reproductive failure in dogs, it should be ruled out before investigating other causes of infertility or abortion (13). However, if reproductive failure is not documented, canine brucellosis can be difficult to diagnose.

Another well-recognized manifestation of infection with $B$. canis is diskospondylitis, which can occur in otherwise healthy dogs or in those with a history of reproductive failure that was treated with antimicrobial drugs $(17,18)$. Infected dogs have a history of lameness, spinal pain, neurologic dysfunction, muscle weakness, or any combination of these signs, caused by vertebral osteomyelitis and intervertebral disc infection (18). Incidence of diskospondylitis is higher in male than female dogs, perhaps because of a reservoir of bacteria in the prostate that results in intermittent bacteremia even in castrated males $(11,17,18)$.

Antimicrobial drug treatment alone after signs of reproductive failure is usually unsuccessful because of the ability of the bacteria to sequester intracellularly for long periods and cause episodic bacteremia (8). The recommended course of treatment is multimodal and includes surgical sterilization and antimicrobial drugs.

\section{Diagnostic Testing in Dogs}

\section{Serology}

The initial diagnostic test for suspected brucellosis cases and the screening tool for evaluating breeding dogs is serologic testing (Table). Serologic tests evaluate antibody response against Brucella spp. cell wall antigens. Brucella spp. have 2 recognized cell wall morphologic appearances based on the structure of the $O$-polysaccharide subunit of lipopolysaccharide: smooth (considered more virulent; includes $B$. abortus, B. suis, and B. melitensis) and rough (B. canis and B. ovis) (25). These differences are noteworthy because serologic tests designed to detect infections with smooth Brucella spp. will not detect infection with $B$. canis.

The serologic methods most commonly used to screen for B. canis infections are the rapid slide agglutination test, 2-mercaptoethanol rapid slide agglutination test, agar-gel immunodiffusion, and ELISA (8). To confirm the results of these screening serologic methods, most diagnostic laboratories use the indirect fluorescent antibody test.

Use of serologic tests to diagnose $B$. canis infection has several pitfalls. The lack of a sensitive and specific screening test hampers the ability of veterinarians to diagnose the disease accurately. These tests are better at detecting early infections but have diminished sensitivity in chronically infected animals, which may be only intermittently bacteremic (19). Using B. canis $\mathrm{M}-$ antigen instead of $B$. ovis antigen reduces nonspecific reactions to the cell wall antigens of other gram-negative bacteria (e.g., Pseudomonas spp., Actinobacillus equuli, Bordetella bronchiseptica) and gram-positive bacteria (e.g., Staphylococcus aureus, S. epidermidis) and improves specificity $(14,26)$. Furthermore, treating serum with 2-mercapthoethanol increases the 
Brucellosis in Dogs and Public Health Risk

Table. Diagnostic tests for Brucella canis in dogs*

\begin{tabular}{|c|c|c|c|c|}
\hline Test type & $\begin{array}{l}\text { Antigen detected or } \\
\text { target DNA }\end{array}$ & Sensitivity, \% & Specificity, \% & Reference \\
\hline \multicolumn{5}{|l|}{ Serologic } \\
\hline Rapid slide agglutination & Cell wall & $50-75$ & 83.34-99.7 & $(19)$ \\
\hline $\begin{array}{l}\text { 2-mercaptoethanol rapid slide } \\
\text { agglutination }\end{array}$ & Cell wall & $31.76-70$ & 100 & (19) \\
\hline $\begin{array}{l}\text { Agar-gel immunodiffusion, cell wall } \\
\text { antigen }\end{array}$ & $\begin{array}{l}\text { LPS, outer membrane } \\
\text { protein }\end{array}$ & $27.98-52.94$ & 100 & (19) \\
\hline ELISA & LPS or CPAg & $88-97$ & $94.3-96.7$ & (20) \\
\hline Immunochromatographic & $\begin{array}{l}\text { R-LPS with outer } \\
\text { membrane proteins }\end{array}$ & 89.58 & 100 & $(21,22)$ \\
\hline \multicolumn{5}{|l|}{ Other } \\
\hline PCR (ITS66 and ITS279) & 16S-23S rRNA gene & 100 & $86.45-100$ & (23) \\
\hline PCR (JPF/JPR) & $\begin{array}{l}\text { Outer membrane } \\
\text { protein } 2\end{array}$ & $\begin{array}{c}16.67 \text { (whole blood); } 92.31 \\
\text { (vaginal swab sample) }\end{array}$ & $\begin{array}{c}100 \text { (whole blood); } 51.92 \\
\text { (vaginal swab sample) }\end{array}$ & (24) \\
\hline
\end{tabular}

specificity of the test by destroying IgM pentamers that can interfere with evaluation of IgG but does not fully eliminate false positives because of heterologous cross-reactions $(14,27)$. Treatment with antimicrobial drugs can affect testing by eliminating bacteremia (8).

\section{Culture}

The standard test for $B$. canis is culture (8). Commonly collected samples include blood, vaginal discharge, and semen. Of these, blood is the most commonly collected; however, because bacteremia can be intermittent, positive animals may be missed $(10,19)$. The best time for culturing Brucella is 2-4 weeks after infection, after demonstration of reproductive failure, when bacteremia is the highest $(8,10,26)$. Culture is not recommended if the dog has received antimicrobial drugs because they will clear the bacteremia regardless of the resolution of systemic disease (8). Culture requires up to 9 days, increasing the risk for exposure of laboratory personnel if the cultures are not handled appropriately (28).

\section{PCR}

Several PCR primers have been designed to detect $B$. canis DNA in whole blood, vaginal secretions, and semen. PCR has the potential as a rapid, discriminatory test to screen dogs, or it can be a useful confirmatory test for seropositive $\operatorname{dogs}(23,24,29)$. However, use of PCR is not yet readily available in most diagnostic laboratories and remains an experimental test.

\section{B. canis Infection in Humans}

Humans acquire $B$. canis infection through direct contact with infected dogs or their reproductive or blood products (30-32). Clinical signs and symptoms include undulant fever, chills, malaise, splenomegaly, and peripheral lymphadenomegaly (33). In humans, diagnosis is often complicated because of the nonspecific signs and symptoms coupled with a low index of suspicion by many physicians. If the disease is part of the differential diagnosis, culture is the only test available for diagnosing $B$. canis infection in humans, and confirmation is problematic because of low-level and intermittent bacteremia (34). Even if physicians suspect brucellosis, diagnoses may be missed because the commercially available serologic tests screen for the smooth Brucella species and will not detect antibodies against $B$. canis (35). Canine serologic tests for $B$. canis infection have been adapted for use in humans, but test results should be interpreted with caution.

Laboratory personnel, veterinarians, and animal caretakers are at increased risk for exposure to $B$. canis $(3,32,36)$. Brucella spp. are considered high-risk pathogens and require a specialized Biosafety Level 3 work space, which if not used can result in laboratory-acquired exposure from a variety of scenarios, such as working with unknown bacterial pathogens on the benchtop (28). Dentinger et al. described an incident in which 31 laboratory workers were exposed to $B$. canis after handling an unknown gram-negative bacterium on the benchtop (10). None became ill with clinical disease, even those characterized as having experienced high-risk exposures (according to Centers for Disease Control and Prevention guidelines) and who declined postexposure prophylaxis (5 of 21 at high risk) (16). One case of laboratory-acquired exposure was documented in a technician who used mouth-pipetting to resuspend the M- strain of $B$. canis; the technician experienced symptoms despite this particular strain being considered avirulent in dogs (37). Additionally, Krueger et al. applied available veterinary serologic diagnostic tests to 2 cohorts of persons with or without occupational exposure to dogs and found a seroprevalence of $3.6 \%$ among those exposed to dogs, which is higher than previously reported seroprevalence of $0.6 \%$ among those with occupational exposure $(3,38)$. Identified risk factors included working as kennel staff, exposure to breeding bitches, and failure to wash hands after caring for a sick dog (3). Of note, in that study, only 2 of the 306 persons with occupational exposure to dogs reported any clinical signs or symptoms associated with brucellosis after contact with dogs who had confirmed brucellosis (3). Unfortunately, the temporality of the onset of clinical signs and symptoms and exposure could not be determined (3). Regardless, these 
findings may suggest that healthy humans might be moderately resistant to clinical illness from $B$. canis infection.

Several case reports highlight pet ownership as a likely risk factor leading to infection in otherwise healthy persons $(9,16,32,33,39)$. In particular, children and immunosuppressed persons might be at higher risk for acquiring the disease $(16,36,39,40)$. Three cases in children $<4$ years of age have been reported $(16,36,39)$. In 1 of the reports, Dentinger et al. described transmission of $B$. canis to a child from an infected puppy that had been purchased from a pet store and was deemed healthy during an initial veterinary visit (16). However, after the child became febrile and $B$. canis infection was diagnosed by blood culture, isolates from the child and puppy were submitted to the Centers for Disease Control and Prevention. The 2 isolates showed close genetic similarity, suggesting that the puppy was the source of infection. Clinical signs did not develop in 4 adults in the same household, all of whom had been exposed to the puppy. Several recent reports of $B$. canis in HIV-infected patients highlight the risk within this population $(31,40,41)$. These cases of $B$. canis infection were linked to ownership of reproductively intact dogs that had a history of reproductive failure and a later diagnosis of $B$. canis infection according to serology and blood culture $(31,40)$.

\section{Public Health Implications}

Brucellosis in dogs occurs worldwide (Figure), but many countries, regardless of their resource level, lack a cohesive plan to respond to cases of this infection in humans or dogs. Brucellosis in humans is notifiable in all 57 states and territories of the United States. Thus, cases must be reported to the National Notifiable Disease Surveillance System; reported in a case report to the Bacterial Special Pathogens Branch at the Centers for Disease Control and Prevention when identified by a health provider, hospital, or laboratory; or both. However, the causative Brucella species is not always reported. As a result, it is difficult to obtain accurate estimates of $B$. canis infections in humans. Despite the presence of this pathogen in geographically and politically diverse locations, few countries have B. canis-specific regulations. A lack of regulatory interest makes it likely that $B$. canis will continue to be an underrecognized pathogen of dogs and humans.

The public health relevance of $B$. canis infection in humans is unclear because much of the information comes from case reports. The perceived infrequency of human infection with $B$. canis and the lack of reliable diagnostic tools for disease detection has led to few serologic surveys in humans. Our current understanding of prevalence of $B$. canis infection in humans comes from a handful of serologic surveys that use diagnostic tests available for dogs and thus may not be truly representative $(3,38,42-44)$.

In the United States, cross-sectional serologic surveys of military recruits and Florida residents and case-control surveys of animal caretakers with occupational exposure to canids documented an extremely low $B$. canis seropositivity $(0.4 \%-0.6 \%)(38,42,44)$. Veterinarians from Florida with occupational exposure to dogs were also surveyed but were all negative according to serologic testing (38). In 1976, a serologic survey in Mexico City, Mexico, evaluated human blood samples from randomly selected patients for B. canis antibodies by using the plate agglutination test; documented seropositivity was $13.3 \%$ (45). More recently, in Brazil, convenience sampling of human blood samples for screening found that $4.6 \%$ of surveyed adults had a positive antibody titer (46). Most serologic studies have relied on random convenience sampling of human blood samples. In contrast, a case-control survey by Monroe et al. documented a high B. canis seropositivity $(80.5 \%)$ in persons with fever of unknown origin, but these results were not confirmed by blood culture (43). Differences between these studies can be attributed to the test used (tube agglutination test vs. microtiter plate agglutination) and the study population.

When compared with owned dogs, stray dogs are more likely to be intact and have a higher documented level of B. canis seropositivity $(45,47)$. A higher burden of canine brucellosis in the stray/roaming dog populations could lead to spillover into the human population in areas with a large number of intact, stray dogs because these dogs are taken into shelters or placed in foster homes pending adoption. In the United States, $\approx 30 \%$ of pet dogs are adopted from animal shelters, and testing for B. canis is not standard procedure before adoption (48). No definitive evidence demonstrates a direct link between the number of reproductively intact, stray dogs in an area and potential for human exposure. Studies that attempt to compare levels of $B$. canis antibodies in humans with results of serologic surveys of dogs may not correlate a positive antibody titer in humans to clinical signs of infection or may not correlate the findings with exposure to stray or owned dogs (45). In the absence of the full epidemiologic picture, it is difficult to draw conclusions between seropositive dogs and the potential for human exposure, but future research could clarify the risk potential.

Another potential source of $B$. canis dissemination is breeding kennels, given the nature of the disease, the fact that animals are housed in close contact, and the constant movement of dogs for breeding or sale (49). Recent outbreaks in kennels in the United States, Hungary, Sweden, and Colombia highlight the link between outbreaks and interregional/international movement of breeding dogs $(5-7,49)$. Unrestricted movement of reproductively intact dogs or puppies is a known risk factor for the spread of infectious diseases and has led to human infection with $B$. canis (16,49). Quarantine periods and premovement health tests of dogs vary by region, but no region tests dogs for brucellosis before they are moved (48). Required testing of 
breeding animals or their offspring before interstate or international movement would decrease the risk for $B$. canis transmission between dogs and from dogs to humans.

Practices to limit the number of intact stray animals include government- or private charity-sponsored sterilization or testing and euthanasia of B. canis-positive dogs. In resource-limited communities, the true risk associated with a large roaming population is unknown, but these dogs should be considered a possible zoonotic risk for humans until new data suggest otherwise. This population of dogs serves to keep brucellosis as an endemic zoonotic disease indefinitely.

The World Health Organization and the World Organisation for Animal Health do not have policies relating to brucellosis caused by B. canis. Perhaps because of a perceived low incidence, many countries also do not have response plans or routine surveillance for $B$. canis in dogs or humans $(5,46)$. In the United States, where $B$. canis was first isolated, the response is piecemeal; however, published recommendations include requiring mandatory reporting of brucellosis in dogs to state health authorities, state health departments to enter into a memorandum of understanding with veterinary diagnostic laboratories to report positive cases to the state health department, and mandatory communication with veterinarians and dog owners to alert them of the zoonotic risk (30). Other measures to prevent zoonotic transmission include confirming the diagnosis with the veterinarian and providing educational materials about the zoonotic potential associated with interacting with a $B$. canis-positive dog (30). One aspect of reducing the zoonotic potential is educating owners about options for managing B. canis-positive dogs, such as sterilization, antimicrobial drug therapy, and repeat testing, or euthanasia if those measures cannot be applied (30). Anyone who has contact with an infected dog should maintain good hygiene standards when handling its urine, feces, or reproductive products (30).

Other methods to decrease the incidence of brucellosis in dogs include improving diagnostic tests and developing a vaccine. Improved diagnostic tests are needed for better evaluation of disease prevalence in at-risk communities and to help physicians and veterinarians more accurately identify cases of disease caused by $B$. canis. In addition to improved diagnostic tests, a $B$. canis vaccine, which is not currently available, could substantially decrease infection incidence in the dog population and thus reduce the risk for transmission to humans.

In conclusion, brucellosis in dogs remains endemic to many parts of the world and without stronger intervention measures will probably remain an underrecognized threat to human health and animal welfare. Future work is required to improve diagnostic assays for humans and animals and to generate policies to prevent the spread of disease. Implementation of mandatory testing before interstate or international movement of dogs would be a good first step.

\section{Acknowledgments}

We thank Cecilia Smith for her technical assistance with developing the map of the serologic data.

Financial support was provided by the American Kennel Club Canine Health Fund 02175-A (to A.M.A.-G.). Student stipend support was provided by National Institutes of Health T32 fellowship 5 T32 OD 11083-7 (to M.E.H.).

\section{About the Author}

Dr. Hensel is a veterinarian and Diplomate of the American College of Veterinary Pathologists. She is currently pursuing a $\mathrm{PhD}$ degree in veterinary pathobiology with an emphasis on infectious disease pathology at Texas A\&M University.

\section{References}

1. Carmichael LE, Kenney RM. Canine abortion caused by Brucella canis. J Am Vet Med Assoc. 1968;152:605-16.

2. Whatmore AM, Koylass MS, Muchowski J, Edwards-Smallbone J, Gopaul KK, Perrett LL. Extended multilocus sequence analysis to describe the global population structure of the genus Brucella: phylogeography and relationship to biovars. Front Microbiol. 2016;7:2049. http://dx.doi.org/10.3389/fmicb.2016.02049

3. Krueger WS, Lucero NE, Brower A, Heil GL, Gray GC. Evidence for unapparent Brucella canis infections among adults with occupational exposure to dogs. Zoonoses Public Health. 2014;61:509-18. http://dx.doi.org/10.1111/zph.12102

4. Jones RL, Emerson JK. Canine brucellosis in a commercial breeding kennel. J Am Vet Med Assoc. 1984;184:834-5.

5. Kaden R, Ågren J, Båverud V, Hallgren G, Ferrari S, Börjesson J, et al. Brucellosis outbreak in a Swedish kennel in 2013: determination of genetic markers for source tracing. Vet Microbiol. 2014;174:523-30. http://dx.doi.org/10.1016/j.vetmic.2014.10.015

6. Castrillón-Salazar L, Giraldo-Echeverri CA, Sánchez-Jiménez MM, Olivera-Angel M. Factors associated with Brucella canis seropositivity in kennels of two regions of Antioquia, Colombia [in Spanish]. Cad Saude Publica. 2013;29:1955-73. http://dx.doi.org/10.1590/0102-311X00133013

7. Gyuranecz M, Szeredi L, Rónai Z, Dénes B, Dencso L, Dán Á, et al. Detection of Brucella canis-induced reproductive diseases in a kennel. J Vet Diagn Invest. 2011;23:143-7. http://dx.doi.org/10.1177/104063871102300127

8. Carmichael LE, Shin SJ. Canine brucellosis: a diagnostician's dilemma. Semin Vet Med Surg (Small Anim). 1996;11:161-5. http://dx.doi.org/10.1016/S1096-2867(96)80028-4

9. Munford RS, Weaver RE, Patton C, Feeley JC, Feldman RA Human disease caused by Brucella canis. A clinical and epidemiologic study of two cases. JAMA. 1975;231:1267-9. http://dx.doi.org/10.1001/jama.1975.03240240037023

10. Wanke MM. Canine brucellosis. Anim Reprod Sci. 2004;8283:195-207. http://dx.doi.org/10.1016/j.anireprosci.2004.05.005

11. Carmichael LE, Joubert JC. Transmission of Brucella canis by contact exposure. Cornell Vet. 1988;78:63-73.

12. Moore JA, Gupta BN. Epizootiology, diagnosis, and control of Brucella canis. J Am Vet Med Assoc. 1970;156:1737-40.

13. Carmichael LE. Canine brucellosis. In: Greene CE, editor. Infectious diseases of the dog and cat. 4th ed. London: Elsevier Health Sciences; 2012. p. 398-411.

14. Carmichael LE, Zoha SJ, Flores-Castro R. Problems in the serodiagnosis of canine brucellosis: dog responses to cell wall and internal antigens of Brucella canis. Dev Biol Stand. $1984 ; 56: 371-83$. 
15. Moore JA. Brucella canis infection in dogs. J Am Vet Med Assoc. 1969;155:2034-7.

16. Dentinger CM, Jacob K, Lee LV, Mendez HA, Chotikanatis K, McDonough PL, et al. Human Brucella canis infection and subsequent laboratory exposures associated with a puppy, New York City, 2012. Zoonoses Public Health. 2015;62:407-14. http://dx.doi.org/10.1111/zph.12163

17. Kerwin SC, Lewis DD, Hribernik TN, Partington B, Hosgood G, Eilts BE. Diskospondylitis associated with Brucella canis infection in dogs: 14 cases (1980-1991). J Am Vet Med Assoc. 1992;201:1253-7.

18. Hurov L, Troy G, Turnwald G. Diskospondylitis in the dog: 27 cases. J Am Vet Med Assoc. 1978;173:275-81.

19. Keid LB, Soares RM, Vasconcellos SA, Megid J, Salgado VR, Richtzenhain LJ. Comparison of agar gel immunodiffusion test, rapid slide agglutination test, microbiological culture and PCR for the diagnosis of canine brucellosis. Res Vet Sci. 2009;86:22-6. http://dx.doi.org/10.1016/j.rvsc.2008.05.012

20. Wanke MM, Delpino MV, Baldi PC. Comparative performance of tests using cytosolic or outer membrane antigens of Brucella for the serodiagnosis of canine brucellosis. Vet Microbiol. 2002;88: 367-75. http://dx.doi.org/10.1016/S0378-1135(02)00152-9

21. Wanke MM, Cairó F, Rossano M, Laiño M, Baldi PC, Monachesi NE, et al. Preliminary study of an immunochroma-tography test for serological diagnosis of canine brucellosis. Reprod Domest Anim. 2012;47(Suppl 6):370-2. http://dx.doi.org/10.1111/rda.12108

22. Keid LB, Diniz JA, Oliveira TM, Ferreira HL, Soares RM. Evaluation of an immunochromatographic test to the diagnosis of canine brucellosis caused by Brucella canis. Reprod Domest Anim. 2015;50:939-44. http://dx.doi.org/10.1111/rda.12612

23. Keid LB, Soares RM, Vieira NR, Megid J, Salgado VR, Vasconcellos SA, et al. Diagnosis of canine brucellosis: comparison between serological and microbiological tests and a PCR based on primers to $16 \mathrm{~S}-23 \mathrm{~S}$ rDNA interspacer. Vet Res Commun. 2007;31:951-65. http://dx.doi.org/10.1007/ s11259-006-0109-6

24. Kauffman LK, Bjork JK, Gallup JM, Boggiatto PM, Bellaire BH, Petersen CA. Early detection of Brucella canis via quantitative polymerase chain reaction analysis. Zoonoses Public Health. 2014;61:48-54. http://dx.doi.org/10.1111/zph.12041

25. Rittig MG, Kaufmann A, Robins A, Shaw B, Sprenger H, Gemsa D, et al. Smooth and rough lipopolysaccharide phenotypes of Brucella induce different intracellular trafficking and cytokine/ chemokine release in human monocytes. J Leukoc Biol. 2003;74:1045-55. http://dx.doi.org/10.1189/jlb.0103015

26. Carmichael LE, Joubert JC. A rapid slide agglutination test for the serodiagnosis of Brucella canis infection that employs a variant (M-) organism as antigen. Cornell Vet. 1987;77:3-12.

27. Mateu-de-Antonio EM, Martín M, Casal J. Comparison of serologic tests used in canine brucellosis diagnosis. J Vet Diagn Invest. 1994;6:257-9. http://dx.doi.org/10.1177/104063879400600220

28. Yagupsky P, Baron EJ. Laboratory exposures to brucellae and implications for bioterrorism. Emerg Infect Dis. 2005;11:1180-5. http://dx.doi.org/10.3201/eid1108.041197

29. Kang SI, Lee SE, Kim JY, Lee K, Kim JW, Lee HK, et al. A new Brucella canis species-specific PCR assay for the diagnosis of canine brucellosis. Comp Immunol Microbiol Infect Dis. 2014;37:237-41. http://dx.doi.org/10.1016/j.cimid.2014.07.003

30. National Association of State Public Health Veterinarians. Public health implications of Brucella canis infections in humans [cited 2016 Apr 4]. http://www.nasphv.org/Documents/ BrucellaCanisInHumans.pdf

31. Lawaczeck E, Toporek J, Cwikla J, Mathison BA. Brucella canis in a HIV-infected patient. Zoonoses Public Health. 2011;58:150-2. http://dx.doi.org/10.1111/j.1863-2378.2010.01334.x
32. Lucero NE, Corazza R, Almuzara MN, Reynes E, Escobar GI, Boeri E, et al. Human Brucella canis outbreak linked to infection in dogs. Epidemiol Infect. 2010;138:280-5. http://dx.doi.org/10.1017/ S0950268809990525

33. Swenson RM, Carmichael LE, Cundy KR. Human infection with Brucella canis. Ann Intern Med. 1972;76:435-8. http://dx.doi.org/ 10.7326/0003-4819-76-3-435

34. Rumley RL, Chapman SW. Brucella canis: an infectious cause of prolonged fever of undetermined origin. South Med J. 1986;79:626-8. http://dx.doi.org/10.1097/ 00007611-198605000-00027

35. Lucero NE, Escobar GI, Ayala SM, Jacob N. Diagnosis of human brucellosis caused by Brucella canis. J Med Microbiol. 2005;54:457-61. http://dx.doi.org/10.1099/jmm.0.45927-0

36. Marzetti S, Carranza C, Roncallo M, Escobar GI, Lucero NE. Recent trends in human Brucella canis infection. Comp Immunol Microbiol Infect Dis. 2013;36:55-61. http://dx.doi.org/10.1016/ j.cimid.2012.09.002

37. Wallach JC, Giambartolomei GH, Baldi PC, Fossati CA. Human infection with M- strain of Brucella canis. Emerg Infect Dis. 2004;10:146-8. http://dx.doi.org/10.3201/eid1001.020622

38. Hoff GL, Nichols JB. Canine brucellosis in Florida: serologic survey of pound dogs, animal shelter workers and veterinarians. Am J Epidemiol. 1974;100:35-9. http://dx.doi.org/10.1093/ oxfordjournals.aje.a112006

39. Tosi MF, Nelson TJ. Brucella canis infection in a 17-monthold child successfully treated with moxalactam. J Pediatr. 1982;101:725-7. http://dx.doi.org/10.1016/S0022-3476(82)80301-6

40. Lucero NE, Maldonado PI, Kaufman S, Escobar GI, Boeri E, Jacob NR. Brucella canis causing infection in an HIV-infected patient. Vector Borne Zoonotic Dis. 2010;10:527-9. http://dx.doi.org/10.1089/vbz.2009.0034

41. Moreno S, Ariza J, Espinosa FJ, Podzamczer D, Miró JM, Rivero A, et al. Brucellosis in patients infected with the human immunodeficiency virus. Eur J Clin Microbiol Infect Dis. 1998;17:319-26. http://dx.doi.org/10.1007/BF01709454

42. Lewis GE Jr, Anderson JK. The incidence of Brucella canis antibodies in sera of military recruits. Am J Public Health. 1973;63:204-5. http://dx.doi.org/10.2105/AJPH.63.3.204

43. Monroe PW, Silberg SL, Morgan PM, Adess M. Seroepidemiological investigation of Brucella canis antibodies in different human population groups. J Clin Microbiol. 1975;2:382-6.

44. Hoff GL, Schneider NJ. Serologic survey for agglutinins to Brucella canis in Florida residents. Am J Trop Med Hyg. 1975;24:157-9. http://dx.doi.org/10.4269/ajtmh.1975.24.157

45. Flores-Castro R, Segura R. A serological and bacteriological survey of canine brucellosis in Mexico. Cornell Vet. 1976;66:347-52.

46. Angel MO, Ristow P, Ko AI, Di-Lorenzo C. Serological trail of Brucella infection in an urban slum population in Brazil. J Infect Dev Ctries. 2012;6:675-9. http://dx.doi.org/10.3855/jidc.2347

47. Brown J, Blue JL, Wooley RE, Dreesen DW. Brucella canis infectivity rates in stray and pet dog populations. Am J Public Health. 1976;66:889-91. http://dx.doi.org/10.2105/AJPH.66.9.889

48. Simmons KE, Hoffman CL. Dogs on the move: factors impacting animal shelter and rescue organizations' decisions to accept dogs from distant locations. Animals (Basel). 2016;6:E11. http://dx.doi.org/10.3390/ani6020011

49. Brower A, Okwumabua O, Massengill C, Muenks Q, Vanderloo P, Duster M, et al. Investigation of the spread of Brucella canis via the U.S. interstate dog trade. Int J Infect Dis. 2007;11:454-8. http://dx.doi.org/10.1016/j.ijid.2006.12.009

Address for correspondence: Martha E. Hensel, Texas A\&M University, 4467 TAMU, College Station, TX 77845, USA; email: mhensel@cvm.tamu.edu 